\title{
Editorial
}

\section{Exploring sociomaterial mediations of human subjectivity}

Subjectivity (2013) 6, 1-11. doi:10.1057/sub.2012.30

Auguste Rodin's bronze sculpture Le Penseur (The Thinker) from 1902 presented an image of Dante deep in thought, pondering The Divine Comedy. The naked sculpture emphasizes how Dante's heroic mind created this masterpiece independently, solely equipped with his bare human faculties, without instruments, without techniques, without social relations, even without clothing. In popular culture, the sculpture has come to symbolize the (gendered) subjectivity of genius, an autonomous, pure and purely individual (male) subject, an ideal worthy of emulation. In line with former volumes of Subjectivity (for example, Blackman et al, 2008), this special issue challenges such individualistic and mentalist visions of the human and contributes to a contextual understanding of human subjectivity.

Of the multiplicity of aspects that have to be taken into account when exploring subjectivity, this special issue goes beyond a focus on the social and societal world and bare human interrelations, and scrutinizes the material world and relations between social beings and technologies, things and materials. Our aim is to invite readers to engage in a broad discussion on how to systematically include technology and materiality in the study of subjectivity. To stimulate that debate, we have collected six articles in this special issue that are each deeply involved with the theoretical, epistemological and empirical concerns of how subjectivity can be conceptualized and explored as a genuinely sociomaterial phenomenon. Together, the papers provide insights into how relations between the social and the material, and indeed the sociomaterial, can be approached, drawing on traditions of thought ranging from psychoanalysis, cultural-historical activity theory, critical psychologies, post-structuralism and feminist theories to science and technology studies (STS), actor-network theory (ANT), post-phenomenology and speculative philosophy. Aside from providing insights into individual approaches, we believe that the way these papers and approaches speak to 
each other, their mutual synergies and the tensions between them, is particularly important in exploring sociomaterial subjectivity. However, tensions exist not only between, but also within papers. In a different way, each paper demonstrates how the study of subjectivity and materiality is a genuinely interdisciplinary endeavour, just as it seems to require the theoretical flexibility of combining approaches. It is just as innovative as it is risky.

This does not mean that the attempt to engage in the study of subjectivity and materiality is new. The interrelation of technology and materiality has been reflected in social and cultural theories since the industrial revolution (for example, Karl Marx, Max Weber, Martin Heidegger, Georg Simmel, Lewis Mumford, Günther Anders, Frankfurt School, ecological movements). Yet only in the recent decades have the social and human sciences come to recognize the central significance of technology and materiality in almost every sphere of human life. Life in the contemporary western world is increasingly characterized by 'postsocial relationships', a term suggested by Karin Knorr Cetina to refer to bonds constructed between humans and objects (Knorr Cetina and Bruegger, 2002). This does not mean that such bonds did not exist in earlier times. However, as the social sciences began to emerge, the question of how to reorganize peoples' social positions and societal interrelations was of crucial concern. Social migration, new forms of governance and changes in schemes of social inclusion and exclusion were pressing problems. These were the problems that the social sciences addressed, and these were the concerns that shaped the sociological gaze (Deleuze, 1979). Even if social problems and social techniques of governance (Rose, 1996) are still widely in evidence in contemporary society, a further matter of concern has come to the fore. Postsocial societies problematize the sociomaterial relations of life with and in social network media, computer games, mobile technologies, robotic care, pre-implementation diagnostics, energy production, climate change and so on.

This development has found academic expression in the emergence of subdisciplines (for example, anthropology of technology, sociology of technology, psychology of technology) and multi-disciplinary programmes such as media studies or STS. Within these fields of study, a body of work has been developed that confronts the controversies and complexities of technological change and tries to understand the creation and transformation of subjectivity in today's sociomaterial world. Such studies sometimes appear in isolation, sometimes in networks, but as yet there has not been any systematic debate of the notion of materiality in the social and human sciences. How can the interconnectedness and interaction between subjectivity and materiality be conceptualized? Do the concepts of subjectivity and materiality need to be reconfigured (Suchman, 2008) when set in relation to one another, and (why) do we need this conceptual distinction at all? What possibilities of influence and choice are attributed to subjects in the way they deal with material things? How can we understand and how can we methodologically approach human experience and practice, 
sociomaterial relations and the embodied actions of material artefacts? How can a social imagination of material creation be developed? And, finally, how do researchers reflect on themselves and their own sociomaterial research practices and techniques?

We can identify two different movements in approaches to these concerns that are central for any discussion of subjectivity and materiality, and of thinking through the sociomaterial mediation of human subjectivity. On the one hand, there are movements of thought exploring technology and materiality from the perspective of subjectivity; on the other, there are movements theorising in terms of the emergence of enacted sociomaterial arrangements, carefully tracing the multiplicity of human and non human actors involved in the mutual becoming of subjectivity and materiality. Both movements of thought permeate the various articles of this special issue. Even if different, even if seemingly opposite, they are not always alternatives. As when looking at a reversible figure, it is often possible to recognize one of these two movements of thought in a text, just a moment after seeing the other. Moreover, both movements share common points of departure.

\section{Points of Departure in the Study of Subjectivity and Materiality}

Both movements of thought challenge the individualistic and mentalist notions of the human being symbolized in Rodin's thinker. They share the assumption that technology and materiality are constituent entities of human experience and practice. Hence, their central concern is to overcome the dichotomy and divide, still widespread, between subjectivity and materiality. This concern runs through all the articles in this special issue, which conceptualize the sociomaterial as united or assembled, as a mutual mediation between subjectivity and materiality, as these being reconfigured or infected and so on.

This leads to a second commonality. With positivist theoretical languages especially imported from experimental and statistical paradigms, the dominant traditions of twentieth-century mainstream psychology and social science reduce the complex relationships between humans and the world to ideas of linear causation. Such structural effect perspectives prescribe an understanding of the world and of materiality as stimuli creating effects in the individual, and radically foreshorten human subjectivity. Here, the human being seems to be solely dependent on external factors, merely responding to stimuli. Through adopting such approaches, mainstream psychologies and social sciences not only established the research position of a distant judging observer (Verran, 2001), but also established a model of passive research objects - and ultimately dissolved human subjectivity. The complexity of the sociomaterial world as enacted, experienced and debated by living persons was reformulated as psychological variables unaffected by the world. Social science and academic psychology not only lost sight of the subjective dimension of human life, they 
also became 'worldless'. The very act of reflecting on how materials do something to or with human beings brings the 'world' back into psychology and the social sciences, and at that very same moment puts subjectivity back on the agenda. Moreover, as the majority of papers in this special issue develop their thoughts on materiality and subjectivity through empirical analyses, the theoretical endeavour of conceptualizing both materiality and subjectivity together is always clearly accompanied by an interest in making psychology and social science 'worldly'.

In investigating subjectivity and materiality, anti-determinism is the third common point of departure. STS, in particular, offers a detailed critique of the idea of technological determinism highlighting how societies and human beings are not just determined by the technological world, but actively engage in it. 'By changing the shape of material things', Langdon Winner (1989, p. 14f) emphasises, 'we also change ourselves. In this process human beings do not stand at the mercy of a great deterministic punch press that cranks out precisely tailored persons at a certain rate during a given historical period. Instead the situation ... is one in which individuals are actively involved in the daily creation and recreation, production and reproduction of the world in which they live'.

'It could have been otherwise' is a founding notion in STS's approach to technology, and runs throughout the various theories collected under this term. Pinch and Bijker (1984), for example, described how technological artefacts cannot be characterised in relation to one essential property, as their use and interpretation will always vary across different social communities. Accordingly, a technology cannot be said to determine specific social or societal effects. Following this line of thought, it would be misleading to conclude from identifying a pattern in an observed social practice that material structures or technologies are governing and organizing that pattern. As technological determinism ignores the workings of subjectivity, the approaches to understanding materiality as determining social practice must be challenged in conceptualisations of materiality and subjectivity. Thus, the attempts in this special issue to theorize materiality and subjectivity together share the common ground of anti-determinism.

On the basis of these shared points of departure, we now turn to the two interconnected but different movements of thought we can identify in the study of subjectivity and materiality.

\section{Exploring Materiality from the Perspective of Subjectivity}

When subjectivity and materiality become matters of concern, it seems obvious to turn to psychology. Throughout the history of psychology we find traditions of thought seeking to transcend individualistic and deterministic 
causal accounts of the human-world relation and focus on human experience and the complex interaction between subject, others and the sociomaterial world. Early reflections on the subjective dimension of material culture can be found in psychoanalysis. 'Man has ... become a kind of prosthetic God', Sigmund Freud (1975, p. 91) wrote in 1929, 'when he puts on all his auxiliary organs, he is truly magnificent; but those organs have not grown on to him and they still give him much trouble at times'. Freud recognized that science and technology not only offer a general ease of life and increasing freedom from natural constraints, but they can also express the darker sides and destructive passions of the human being. Psychoanalytical approaches interpret the development of material culture in the light of people's internal psychic structures and the psychodynamics of human drives. Furthermore, they also reflect on the role of everyday material things in human development (for example, as 'transitional objects', Winnicott, 1971). Psychoanalytical concepts have been taken up in what could be called 'subject-orientated STS'. Sherry Turkle (2011) and her studies into the relationship between human subjects and computers have been influential in this tradition of thought. In her exploration of the digital world and how it is experienced and lived by the individual subjects, Turkle defines computers as evocative objects. Her research engages with the perspectives of the subjects, and illustrates in detail how the material objects of the digital world evoke specific inter-subjective relations, everyday practices, and the possibilities of and limitations on thinking about oneself and the world. Inspired by psychoanalysis, media studies and the concept of material/immaterial artefacts as evocative objects, Christina Schachtner (e.g., 1997) contributed to an interactionist approach to subjectivity and technology. In Digital Media Evoking Interactive Games in Virtual Space, her article for this special issue, she explores the role of digital media in the construction of the subject.

The cultural-historical activity theory emerging in the 1920s is a further tradition of thought realizing the central importance of materiality for the creation of human subjectivity. In Artefacts that Talk, Cathrine Hasse presents an empirical analysis of the robot 'Paro', used in care for the elderly. She points out that artefacts like 'Paro' relate to humans in a dual way, as material tools as well as subjective interpretive signs. Activity theory was developed by the Moscow 'troika' of Lev Vygotsky, Alexei Leont'ev and Alexander Luria. While Vygotsky's developmental psychology is best known in English-speaking academia, it was Leont'ev (1978) who worked most on subjectivity, or personality as he coined it. This tradition of thought is based on the assumption that higher psychological processes emerged in phylogenesis simultaneously with the capacity to produce and modify material objects as a means of regulating human interactions with the world and one another, and that this development was a phylogenetic prerequisite for the formation of human personality. 'Man differs from animal in that he [sic!] can make and use tools', explained Luria in 1928, these tools 'not only radically 
change his conditions of existence, they even react on him in that they effect a change in him and his psychic condition' (p. 493). Here material artefacts are understood both as ideal and material and the questions centre on how the tools and signs are incorporated into goal-directed human action. Michael Cole (1998, p. 117) explains the dual nature of artefacts as follows: 'By virtue of the changes wrought in the process of their creation and use, artefacts are simultaneously ideal (conceptual) and material. They are ideal in that their material form has been shaped by their participation in the interaction of which they were previously a part and which they mediate in the present'. In this school of thought, detailed models of how material artefacts mediate human action have continued to be developed and refined, and are still used today especially in research on human development, learning and work (Wartofsky, 1973; Engeström et al, 1999; Kontopodis et al, 2011). In an innovative move, Hasse combines in her paper cultural-historical activity theory's approach to subjectivity and materiality with post-phenomenology, providing a more nuanced understanding of technology as multi-stable.

Drawing on the cultural-historical school, critical psychologies (especially in the German and Scandinavian tradition) refined the historical analyses of the psyche and developed a detailed conceptual understanding of the sociomaterial mediation of human subjectivity. In an extensive analysis of the phylogenetic development of the psyche, Klaus Holzkamp $(1983,2013)$ described how, on the path to becoming human, the capacity of the psyche to manipulate and utilize things developed into the ability to create and use material tools and the fabrics of human life. Furthermore, Holzkamp reconstructed a parallel process, whereby the initial capacity to communicate phonetically within social groups developed to produce language and consciousness, which are not only the prerequisites of science and knowledge, but underlie the very possibility of communal understanding. This is what makes humans uniquely human: they are not simply living with others of their species in a direct relationship to a preexisting 'natural' world; instead, they actively and consciously create their own societal and material world, collectively and in accordance with their needs, plans and ideas. It is this living through social and material structures that humans (in contrast to other life forms) have themselves constructed which allows us to speak of sociomaterially mediated subjectivity: a life process of the human subjects mediated by social and material structures of their own creation and a process that humans can (potentially) grasp, use and change.

Thus, according to dialectical materialist psychologies, it makes no sense to try to understand the material world in abstraction from human subjects and their inner relations to it. Humans create the world as subjects within specific linguistic and cultural contexts, communities, institutions and work structures that is, in a sociomaterially mediated form. However, we are also directly confronted with the material artefacts: we live our lives in and through them; and, in this process, we change ourselves. Therefore, human subjects are not 
involved in a one-sided relationship to the material artefacts and conditions, simply being affected by them; the situation is rather that of a dialectical two-sided relationship, where humans are both affected and affecting. On the one hand, this relationship involves appropriating artefacts - using them and realizing their meaning. But on the other, humans are also part of producing and co-producing things. According to critical psychology, it is precisely this two-sided nature of human agency that constitutes the specificity of human subjectivity. From this perspective, the epistemology of the study of subjectivity and materiality must therefore reflect this twofold nature of human subjectivity and agency.

Drawing on 'critical STS' (Winner, 1996; Hess, 1997), more recent approaches in critical psychology explore the dialectics of technology and materiality and realize that they represent not just human accomplishments expanding human possibilities of action, but contradictory structures and forms embodying specific interests, ideologies, power and politics. Therefore, they try to develop two-sided approaches, not just exploring the experiences and activities of individual subjects in their engagement with things, but also examining the discursive-material relationalities (Walkerdine, 2007) as well as the materiality of everyday practice (Costall and Dreier, 2006) and the experiences and actions materialized in the things themselves (Schraube, 2009). On the basis of critical psychological theories of subjectivity as well as a discussion of STS and its efforts to overcome the dichotomy between humans and technology, Ernst Schraube argues in First-Person Perspective and Sociomaterial Decentering for a systematic inclusion of (inter-) subjectivity and the first-person perspective in the social study of technology.

\section{Exploring the Emergence of Enacted Sociomaterial Arrangements and the Mutual Becoming of Subjectivity and Materiality}

In order to understand the second movement of thought, it might help to return to activity theory's concept of personality as a phylogenetic result building on a basic differentiation between humans and animals, and thus between human and nature. In his discussion of modernity, Latour (1993b) argues that nature did not exist before human culture. The phenomenon in the world that we understand as 'nature' is an invention. According to Latour's ANT, only when humans think of and are enacted as creatures with unique qualities does nature emerge as the 'other' to humans. Typically, the qualities enacted as being in contrast to nature are experience, emotion, interpretation, social relations, history, culture and subjectivity. In other words, the view that in particular subjectivity, culture etc. should be tied to the human while animals, materials and other things should be 'natural' and thus nonhuman is emerging in a world that enacts itself through such distinctions. Science has among others contributed significantly to inserting and maintaining this view and thus to the anthropocentric way of treating materiality, nature etc. 
Accordingly, ANT argues that we should not take the boundaries between materiality and subjectivity for granted prior to empirical study, or even the existence of entities such as subjects or materiality. We exclude a lot of questions concerning materiality and subjectivity if differences between them are set prior to empirical studies, the argument goes (Sørensen 2007; 2009). From an ANT point of view, theories approaching sociomaterial relations from a subject perspective give us no reason to question whether the human beings we talk to in empirical studies actually possess subjectivity, or whether they are different from animals, or indeed from the tools they use to make their lives understandable to us. Subjectivity is taken for granted when doing empirical research. ANT turns this upside down: Rather than inquiring what people feel, think and do based on relations between their subjectivity and material things, ANT would enquire into how they are made into subjects that feel, think and act alongside with how materials are made passive, if that indeed is what happens. In her paper on Human Presence Estrid Sørensen explains from an ANT perspective how children in a school class came to be enacted as a team in one situation and as a collective in another, through the specific sociomaterial configurations of those two situations. These ways of being present in the classroom were genuinely sociomaterial and according to Sørensen it would be a misunderstanding of the situations to point to subjectivity and materiality as in any way existing separately. Typically, ANT and similar approaches understanding distinction between the social and the material as emerging (and disappearing) in and through practice apply notions such as hybridity, heterogeneity (Latour, 2005) or even cyborg (Haraway, 1991) to talk about the entanglement of sociomaterial - 'or subjectomaterial' - phenomena.

To date, only very few studies on subjectivity have been done from an ANT perspective. Developed in STS, an early and central focus in ANT was on providing different accounts of scientific and technological development from the traditional human-centred ones celebrating such developments as achievement of great human personalities (Beck et al, 2012). Latour (1993a) studied the invention of pasteurization not as a heroic innovation mastered by Pasteur, but as an effect of multiple heterogeneous efforts and distributed sociomaterial agency, suggesting a radically different model from Rodin's on how to conceptualize human action and invention. The debates in ANT on material agency have been important in turning the scholarly focus away from the human as a natural source of agency. Instead, they have opened up possibilities for a decentred examination of practices as not mainly governed and enacted by human actors, but emerging as the effects of specifically arranged sociomaterial processes. With perspectives decentring from the human as a central theoretical point among ANT scholars, the interests in the human and in subjectivity have been rather sporadic.

In A Philosophy of Interstices, Didier Debaise presents Alfred North Whitehead's process theory, which is a further useful approach in understanding 
subjectivity and materiality through the movement of thought of emerging distinctions. Within this approach, we must envision thunder, cells, the brain or subjects as societies, as ecosystems of relations, spread out in all directions. Rather than claiming that subjects and materials are the same phenomena, this view argues that such phenomena share a need to be determined before they become distinct. Process theory establishes this common ground for all phenomena. However, although it is a common ground with no actual existence aside from the analytical tool through which it works, it nonetheless enables analyses tracing the trajectories defining 'a society as physical or as living, a reality as sensory or ideal, real or imagined' (Debaise, 2013). Whitehead differentiates between physical and living societies in terms of how they are affected by their environment and the exchanges, destructions and transformations occurring within them. Process theory thus provides us with tools to think of subjectivity and materiality, not as related entities but rather as processes of interessement (Stengers, 2000).

On the basis of the complexities they encounter in their empirical work, scholars are increasingly seeking to identify an epistemology allowing them to explore the constitution of subjectivities in their complex relation to social, technological, and other material as well as discursive forces (for example, in this journal: Mol, 2008; Stengers, 2008; Bauchspies and Puig de la Bellacasa, 2009). Hence, Lis Højgaard and Dorte Marie Søndergaard suggest working on a new-materialist framework. Drawing on Karen Barad's 'agential realism', they propose reformulating the notion of 'interaction' as 'intra-action': 'We argue that subjectivity should be seen as intra-acting with and thereby also enacted by discursive as well as material agentiality' (2011, p. 349). In Virtual Materiality, Potentiality and Subjectivity in this volume, Søndergaard combines this approach with Agamben's notion of potentiality to reach an understanding of how dreams, as probably the most 'immaterial' we can imagine, come to be related to material interactions in children's video game play.

The articles in this special issue demonstrate how concepts in psychology, philosophy and STS can help to explore materiality and human subjectivity together. We hope that the encounter of scholars with different theoretical inspirations will help bringing out similarities and differences in theorizing and investigating technological practice and will demonstrate the importance and challenges of including materiality into the study of subjectivity.

\section{References}

Bauchspies, W.K. and Puig de la Bellacasa, M.P. (2009) Re-tooling subjectivities: Exploring the possible with feminist science and technology studies. Subjectivity 28: 227-228.

Beck, S., Niewöhner, J. and Sørensen, E. (2012) Science and Technology Studies: Eine sozialanthropologische Einführung. Bielefeld, Germany: Transcript.

Blackman, L., Cromby, J., Hook, D., Papadopoulos, D. and Walkerdine, V. (2008) Creating subjectivities. Subjectivity 22: 1-27. 
Cole, M. (1998) Cultural Psychology: A Once and Future Discipline. Cambridge, MA: Harvard University Press.

Costall, A. and Dreier, O. (eds.) (2006) Doing Things with Things: The Design and Use of Everyday Objects. Aldershot, UK: Ashgate Publishing.

Debaise, C. (2013) A philosophy of interstices: Thinking subjects and society from Whiteheads's philosophy. Subjectivity 6(1): 101-111.

Deleuze, G. (1979) Introduction. In: J. Donzelot (ed.) The Policing of Families: Welfare Versus the State. London: Hutchinson.

Engeström, Y., Miettinen, R. and Punamäki, R.-L. (eds.) (1999) Perspectives on Activity Theory. Cambridge, UK: Cambridge University Press.

Freud, S. (1975) Civilization and its discontents. In: J. Strachey (ed.) The Standard Edition of the Complete Psychological Works of Sigmund Freud, Vol. XXI. London: Hogarth Press, pp. 55-145.

Haraway, D.J. (1991) Simians, Cyborgs, and Women: The Reinvention of Nature. New York: Routledge.

Hasse, C. (2013) Artefacts that talk: Mediating technology as multistable signs and tools. Subjectivity 6(1): 79-100.

Hess, D.J. (1997) If you're thinking of living in STS. A guide for the perplexed. In: G.L. Downey and J. Dumit (eds.) Cyborgs \& Citadels: Anthropological Interventions in Emerging Sciences and Technologies. Santa Fe, NM: School of American Research Press.

Højgaard, L. and Søndergaard, D.M. (2011) Theorizing the complexities of discursive and material subjectivity: Agential realism and poststructural analyses. Theory \& Psychology 21(3): 338-354.

Holzkamp, K. (1983) Grundlegung der Psychologie. Frankfurt/M, Germany: Campus.

Holzkamp, K. (2013) The development of critical psychology as a subject science. In: E. Schraube and U. Osterkamp (eds.) Psychology from the Standpoint of the Subject: Selected Writings of Klaus Holzkamp. Basingstoke, UK: Palgrave Macmillan, pp. $28-45$.

Knorr Cetina, K. and Bruegger, U. (2002) Traders' engagement with markets: A postsocial relationship. Theory, Culture and Society 19(5-6): 161-185.

Kontopodis, M., Wulf, C. and Fichtner, B. (eds.) (2011) Children, Development and Education. Cultural, Historical, Anthropological Perspectives. Dordrecht, the Netherlands: Springer.

Latour, B (1993a) The Pasteurisation of France. Cambridge, MA: Harvard University Press.

Latour, B. (1993b) We Have Never Been Modern. Cambridge, MA: Harvard University Press.

Latour, B. (2005) Reassembling the Social: An Introduction to Actor-Network Theory. New York: Oxford University Press.

Leont'ev, A.N. (1978) Activity, Consciousness, and Personality. New Jersey: Prentice-Hall.

Luria, A.R. (1928) The problem of the cultural behavior of the child. Journal of Genetic Psychology 35(4): 493-508.

Mol, A. (2008) I eat an apple: On theorizing subjectivities. Subjectivity 22: 28-37.

Pinch, T.J. and Bijker, W.E. (1984) The social construction of facts and artefacts: Or how the sociology of science and the sociology of technology might benefit each other. Social Studies of Science 14(3): 399-441.

Rose, N. (1996) The death of the social? Re-figuring the territory of government. Economy and Society 25(3): 327-356. 
Schachtner, C. (ed.) (1997) Technik und Subjektivität. Das Wechselverhältnis zwischen Mensch und Computer aus interdisziplinärer Sicht. Frankfurt/M, Germany: Suhrkamp.

Schachtner, C. (2013) Digital media evoking interactive games in virtual space. Subjectivity 6(1): 33-54.

Schraube, E. (2009) Technology as materialized action and its ambivalences. Theory \& Psychology 19(2): 296-312.

Schraube, E. (2013) First-person perspective and sociomaterial decentering: Studying technology from the standpoint of the subject. Subjectivity 6(1): 12-32.

Søndergaard, D.M. (2013) Virtuality, potentiality and subjectivity: How do we conceptualize the real-virtual interaction that is embodied and enacted in computer gaming, imaginary worlds and dreams? Subjectivity 6(1): 55-78.

Sørensen, E. (2007) The time of materiality. Forum Qualitative Social Research 8(1), Art. 2, http://nbn-resolving.de/urn:nbn:de:0114-fqs070122.

Sørensen, E. (2009) The Materiality of Learning. Cambridge, US: Cambridge University Press.

Sørensen, E. (2013) Human presence: Towards a post-humanist approach to experience. Subjectivity 6(1): 112-129.

Stengers, I. (2000) The Invention of Modern Science. Minneapolis, MN: University of Minnesota Press.

Stengers, I. (2008) Experimenting with refrains: Subjectivity and the challenge of escaping modern dualism. Subjectivity 22: 38-59.

Suchman, L. (2008) Human-machine Reconfigurations: Plans and Situated Actions. Cambridge, USA: Cambridge University Press.

Turkle, S. (2011) Alone Together: Why We Expect More from Technology and Less from Each Other. New York: Basic Books.

Verran, H. (2001) Science and an African Logic. Chicago, IL: University of Chicago Press.

Walkerdine, V. (2007) Children, Gender, Video Games: Towards a Relational Approach to Multimedia. London: Palgrave Macmillan.

Wartofsky, M. (1973) Models: Representation and the Scientific Understanding. Dordrecht, the Netherlands: Reidel.

Winner, L. (1989) The Whale and the Reactor: A Search for Limits in an Age of High Technology. Chicago, IL: University of Chicago Press.

Winner, L. (1996) The gloves come off: Shattered alliances in science and technology studies. In: A. Ross (ed.) Science Wars. Durham, NC: Duke University Press, pp. 102-113.

Winnicott, D.W. (1971) Playing and Reality. London: Tavistock.

Ernst Schraube

Roskilde University, Denmark

E-mail:schraube@ruc.dk

Estrid Sørensen

Ruhr-University Bochum, Germany

E-mail: estrid.sorensen@rub.de 